\title{
Formulation Of The Simulation Cluster Modelling System DeVelopment Problem
}

\author{
Alexandr Vendin Irina Karpova
}
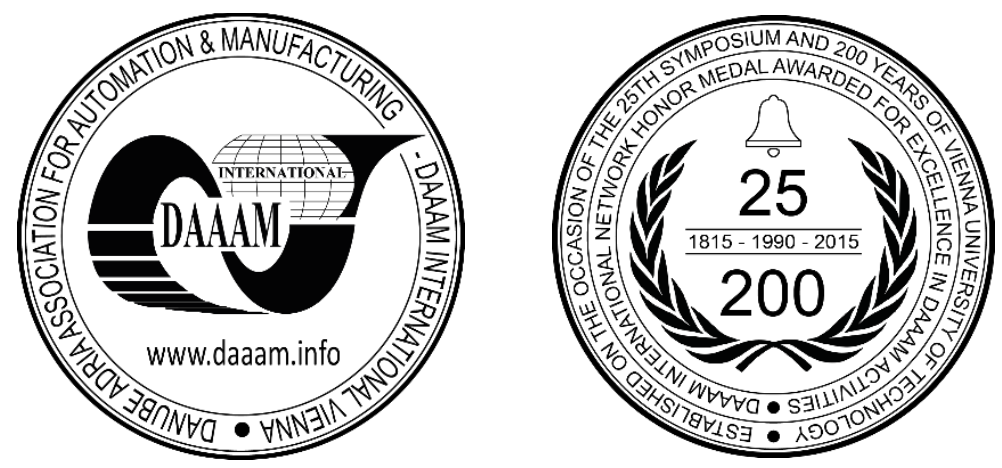

This Publication has to be referred as: Vendin, A[lexandr] \& Karpova, I[rina] (2018). Formulation of the Simulation Cluster Modelling System Development Problem, Proceedings of the 29th DAAAM International Symposium, pp.1125-1128, B. Katalinic (Ed.), Published by DAAAM International, ISBN 978-3-902734-20-4, ISSN 1726-9679, Vienna, Austria

DOI: $10.2507 / 29$ th.daaam.proceedings. 160

\begin{abstract}
The paper deals with the problem creation of a simulation system. The problem is that existing systems, such as Starlogo Nova, Swarm, Mason, TeamBots, Ascape, Stage, V-REP, do not allow in the complex to simulate the physical properties of the object, implement elements of robots, maintain communication between agents, maintain a large number of agents, support the use of clusters and use social-oriented libraries. This ultimately significantly reduces the computational speed. To overcome these difficulties, the structure of a new system of simulation is proposed. At the center of the new system is a calculation module with the possibilities of parallelizing the computational process within a single computer. The module supports distributed computing, if the system is used in a computer network. A variant of the structural scheme of the modeling system is also offered, which includes a calculation module, consisting of a parallel programming support module, a distributed computing support module, an agent module and a simulation environment module. In addition, the proposed structural scheme includes a visualizer, combining the controller/management console and the graphic user interface. The functioning of the system depends on the choice of the basic algorithms that ensure the operation of the simulation system. Offered structure of the system of imitation simulation will allow raising the speed of calculations. Modular system makes it possible to change the configuration of the system with the replacement of some functioning algorithms to others. At the same time, the effective operation of the simulation system, according to the proposed scheme, is not possible without the development of individual software, using high-level programming languages such as $\mathrm{C}++$ or Java.
\end{abstract}

Keywords: collective of robots; simulation modelling; clusters; agent modelling

\section{Introduction}

One of the prospective areas in the development of robotics and artificial intelligence is the possibility of using a team of robots to solve various problems. Through the interaction of objects in the group, the robot team can do complex tasks, objects of interaction themselves will have a relatively simple structure [1]. When developing such robotic systems, the use of simulation modeling is effective. Agent simulation simplifies the task of designing and debugging robotic systems. To carry out simulation models of large scale, more and more computing resources are required [2]. 
The problem is that existing systems, such as Starlogo Nova[3], Swarm[4], Mason[5], TeamBots[6], Ascape[7], Stage[8], V-REP[9], do not allow in the complex to simulate the physical properties of the object, implement elements of robots, maintain communication between agents, maintain a large number of agents, support the use of clusters and use social-oriented libraries. This ultimately significantly reduces the computational speed. Below are the results of studies on the development of a structural scheme of the simulation system, which takes into account the individual shortcomings of existing systems and provides an increase in the speed of calculations, and also providing the possibility of changing the configuration of the system with the replacement of some functioning algorithms on the others.

\section{General requirements for the simulation system}

The simulation system must meet a number of requirements. First, the simulation system must be well scalable. The system should be able to perform the simulation using computational clusters. Parallelization of the code and its synchronization should be done by the system independently, without user intervention [10]. The simulation system should support of certain features of agent systems in general and their implementation in the form of libraries.

The simulation system should support concept of an agent, interaction between agents, environment, laws of interaction with the environment, space, time. The simulation system should realize basic structures and mechanisms of social behavior: individual mental differences, differentiation of functions, local interaction of individuals and language communication, formation of coalitions, emergence of a hierarchical structure. The system should support the creation of models of the internal and external worlds of the agent.

\section{Functional requirements for the simulation system}

The basic functional requirements for the modeling library (or environment) for collectives with a social structure in the field of robotics include:

- Scalability, leverage of parallel computing systems;

- Support for a certain functionality of agent systems. The implementation of such functionality in the form of libraries with agent support, interaction between agents, support of the environment, laws of interaction with the environment and support for space and time;

- Implementation of basic mechanisms of social behavior and structures. Addition and expansion of such mechanisms as individual mental differences, differentiation of functions;

- Support for creating models of the internal and external worlds of the agent;

- Support of models with several interacting (but distinct) groups of agents.

It is also necessary to identify additional important technical requirements for the use of the system by different groups of researchers:

- Ability to integrate code into a third-party user-friendly graphical interface, implement a basic interface for interacting with the simulation system and visualize the data used in the model;

- Export data into open formats (CSV, GraphML, etc.) for data transfer and possible use in other tools;

- $\quad$ Project implementation in open source [11];

- Possibility of code modification through the support of plug-ins or other standard ways to extend the functionality and fix bugs. Expandability to a larger class of supported systems.

\begin{tabular}{|c|c|c|c|c|c|c|c|}
\hline Modeling system & $\begin{array}{c}\text { StarLogo } \\
\text { Nova }\end{array}$ & Swarm & Mason & TeamBots & Ascape & Stage & $\begin{array}{c}\text { V- } \\
\text { REP }\end{array}$ \\
\hline $\begin{array}{c}\text { Simulating the } \\
\text { physical properties of } \\
\text { an object }\end{array}$ & - & - & - & - & - & - & - \\
\hline $\begin{array}{l}\text { Implementing Robot } \\
\text { Element Libraries }\end{array}$ & - & - & - & + & - & + & + \\
\hline $\begin{array}{l}\text { Availability of support } \\
\text { for communication } \\
\text { between agents }\end{array}$ & + & + & + & + & + & + & - \\
\hline $\begin{array}{c}\text { Support for a large } \\
\text { number of agents }\end{array}$ & + & + & + & + & + & + & - \\
\hline Support level & + & - & +- & - & +- & + & + \\
\hline $\begin{array}{c}\text { Support for } \\
\text { calculations on clusters }\end{array}$ & - & - & - & - & - & - & - \\
\hline $\begin{array}{l}\text { Availability of socially } \\
\text { oriented libraries }\end{array}$ & - & - & - & - & - & - & - \\
\hline
\end{tabular}

Table 1. The results of the analysis of existing systems of simulation modeling 
Modeling systems with support for agent modeling are presented in Table 1 together with the result of the analysis of these systems. As can be seen from Table 1, none of the considered systems meets the specified requirements in full. An important drawback is that these systems do not support calculations on clusters.

\section{Creation of the general structure of the simulation system}

The most important and basic part of the simulation system is its core. Figure 1 suggests a variant of the structural scheme of simulation modeling. The core of the modeling system is its calculation module, in which the state of the model changes. The implementation of simulation is carried out on the basis of the basic algorithms that are laid in the calculation module. To fulfill the requirements for the modeling system, the multithreaded programming laid in base of calculation module. This makes it possible to parallelize the computing process within a single computer and perform distributed computing, if the system is deployed on the computer network. The agent module is responsible for presenting of elementary robots in the system. The environment/space module will control the position of agents in space during the simulation. At the same time, the effective operation of the simulation system according to the proposed scheme is not possible without the development of individual software using high-level programming languages such as $\mathrm{C}++$ or Java.

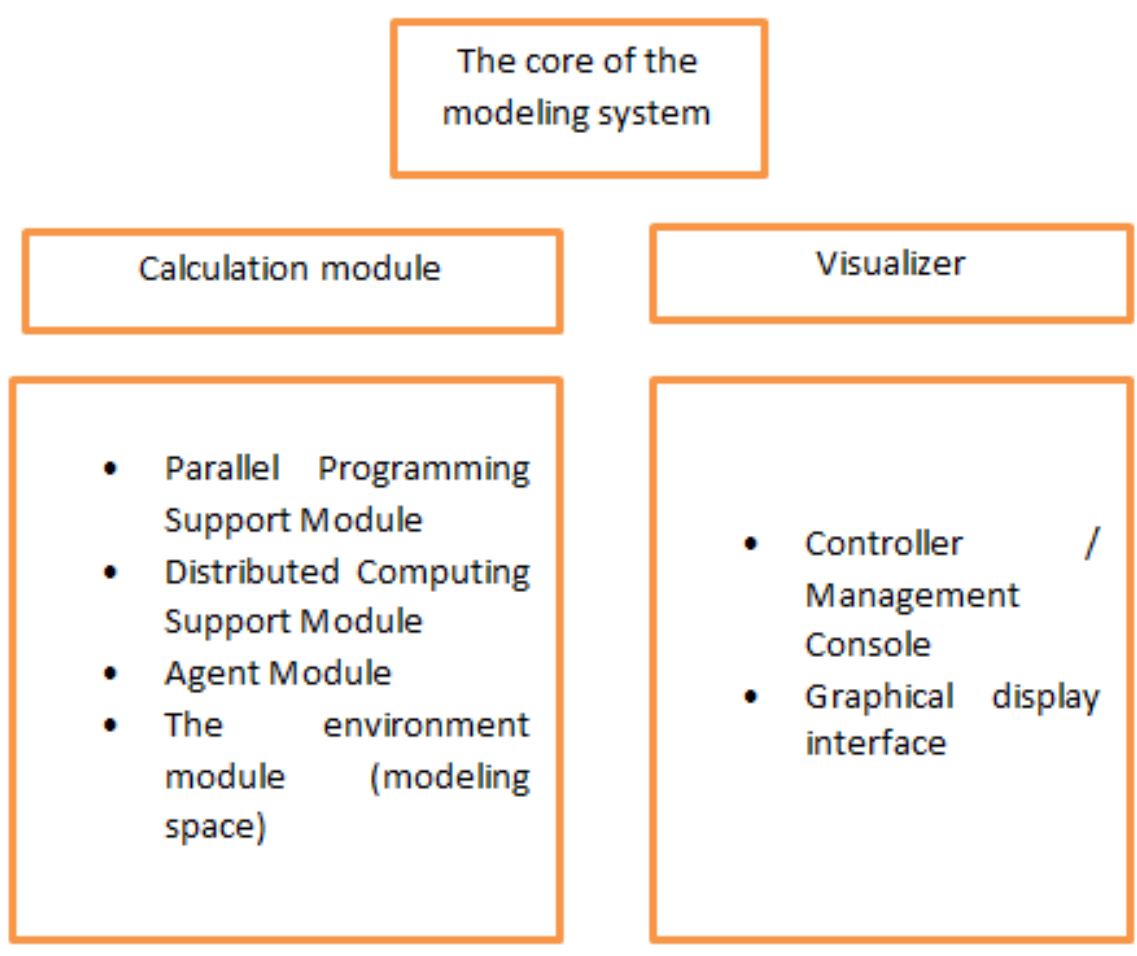

Fig. 1. Simulation system circuit

\section{Conclusion}

Simulation modeling can be effectively applied in the development of robotic systems. The problem is that existing systems, such as Starlogo Nova, Swarm, Mason, TeamBots, Ascape, Stage, V-REP, do not allow in the complex to simulate the physical properties of the object, implement elements of robots, maintain communication between agents, maintain a large number of agents, support the use of clusters and use social-oriented libraries. This ultimately significantly reduces the computational speed.

To overcome these difficulties, the structure of a new system of simulation is proposed. At the center of the new system is a calculation module with the possibilities of parallelizing the computational process within a single computer. The module supports distributed computing, if the system is used in a computer network. A variant of the structural scheme of the modeling system is also offered.

The functioning of the system depends on the choice of the basic algorithms that ensure the operation of the simulation system. Offered structure of the system of imitation simulation will allow raising the speed of calculations. Modular system makes it possible to change the configuration of the system with the replacement of some functioning algorithms to others. At the same time, the effective operation of the simulation system according to the proposed scheme is not possible without the development of individual software using high-level programming languages such as $\mathrm{C}++$ or Java. 


\section{References}

[1] Karpov V. (2016) Models of social behavior in the group robotics // UBS. 2016. No 59. pp. 165-232.

[2] Okol'nishnikov V.V, Rudometov S.V. (2008) A portable simulation system for multiprocessor computing systems // Trudy mezhdunarodnoj nauchnoj konferencii «Parallel'nye vychislitel'nye tekhnologii (pavt'2008)». - SanktPeterburg, 2008. - S. 427-432.

[3] StarLogo. (2018) Available from: https://ru.wikipedia.org/wiki/StarLogo Accessed: 2018-05-02

[4] Swarm:Software main page (2018) Available from: http://www.swarm.org/wiki/Swarm:Software_main_page Accessed: 2018-05-04

[5] Multiagent Simulation And the MASON Library (2018) Available from: https://cs.gmu.edu/ eclab/projects/mason/manual.pdf Accessed: 2018-05-05

[6] TeamBotsTM 2.0 (2018) Available from: https://www.cs.cmu.edu/ trb/TeamBots/ Accessed: 2018-05-04

[7] Ascape Guide (2018) Available from: http://ascape.sourceforge.net/index.html\#Contact Accessed: 2018-05-04

[8] The Player Project (2018) Available from: http://playerstage.sourceforge.net/ Accessed: 2018-05-04

[9] Lenka Pitonakova, Manuel Giuliani1, Anthony Pipe, and Alan Winfield (2018) Feature and performance comparison of the V-REP, Gazebo and ARGoS robot simulators // Lecture Notes in Computer Science 2018

[10] Rovbo M.A., Ovsyannikova E.E., Chumachenko A.A. (2017) Review of simulation modeling tools for robot groups with social organization elements // Software \& Systems. 2017. No 3 (30). pp. 425-434.

[11] Open Source Initiative. The Open Source Definition. 2007. (2017) Available from: https://opensource.org/osd Accessed: 2017-01-08 